\title{
Dyslipidemia associated with subclinical hypothyroidism in Eastern Nepal
}

\author{
Rajaram Yadav', Vishwajeet Rohil2, Ashwini Kumar Nepal', Basanta Gelal', Rajendra Kumar Chaudhari', \\ Punam Jha ${ }^{1}$, Shreejana Shrestha', Madhab Lamsal', Nirmal Baral' ${ }^{1}$ \\ ${ }^{1}$ Department of Biochemistry, B.P. Koirala Institute of Health Sciences, Dharan, Nepal, ${ }^{2}$ Department of Clinical Biochemistry, Vallabhbhai Patel \\ Chest Institute, University of Delhi, Dehli, India
}

Submitted: 04-12-2013

Revised: 10-12-2013

Published: 10-03-2014

A B S TR A C T

Objectives: The present study was conducted aiming to investigate lipid profile in patients with subclinical hypothyroidism as compared to age and sex matched controls. Methods: The study population consisted of total 80 subjects; 40 patients (cases) and 40 controls. Serum free tri-iodothyronine $\left(\mathrm{fT}_{3}\right)$ and free thyroxine $\left(\mathrm{fT}_{4}\right)$ were estimated by microplate competitive enzyme immunoassay, and thyroid stimulating hormone (TSH) measured by sandwich enzyme immunoassay. Lipid profile tests: Total Cholesterol, triglycerides, high density lipoprotein (HDL) cholesterol were estimated by enzymatic methods and low density lipoprotein cholesterol (LDL) was calculated by Friedewald's formula. Results: Significant differences were observed between lipid parameters in case Vs controls: total cholesterol $(4.9 \pm 1.1 \mathrm{Vs} 4.3 \pm 1.0 \mathrm{mmol} / \mathrm{L}, \mathrm{P}=0.03)$, triglycerides $(1.9 \pm 0.7 \mathrm{Vs} 1.6 \pm 0.6 \mathrm{mmol} / \mathrm{L}$, $\mathrm{P}=0.02)$ and $\mathrm{LDL}$ cholesterol levels $(3.5 \pm 1.1 \mathrm{Vs} 2.9 \pm 0.9 \mathrm{mmol} / \mathrm{L}, \mathrm{P}=0.02)$. In case $\mathrm{Vs}$ controls no significant differences were observed between HDL Cholesterol (1.1 $\pm 0.2 \mathrm{Vs}$ $1.1 \pm 0.7 \mathrm{mmol} / \mathrm{L}, \mathrm{P}=0.07), \mathrm{VLDL}(0.9 \pm 0.4 \mathrm{Vs} 0.8 \pm 0.3 \mathrm{mmol} / \mathrm{L}, \mathrm{P}=0.1)$ and Cholesterol/ HDL ratio $(4.48 \pm 1.40 \mathrm{Vs} 4.06 \pm 0.89, \mathrm{P}=0.118)$. Elevated $\mathrm{TSH}$ level were found in cases Vs controls $(12.42 \pm 7.08 \mathrm{Vs} 2.69 \pm 0.20 \mathrm{mIU} / \mathrm{L}, \mathrm{P}=0.01)$ which was statistically significant. The subjects on control group were euthyroid, however increased $\mathrm{fT}_{3}(3.9 \pm 0.8 \mathrm{Vs} 4.6 \pm 0.8$ $\mathrm{pmol} / \mathrm{L}, \mathrm{P}=<0.01)$ and $\mathrm{fT}_{4}(17.1 \pm 3.9 \mathrm{Vs} 21.2 \pm .3 .7 \mathrm{pmol} / \mathrm{L}, \mathrm{P}=<0.01)$ values were observed in controls than cases, which was statistically significant. Conclusion: The results of the present study suggest that cases of subclinical hypothyroidism are at risk of dyslipidemia as compared to controls. Large population based studies are needed to generalize these findings and establish the therapeutic guidelines for implementing lipid lowering agents in subclinical hypothyroidism.

Access this article online

Website:

http://nepjol.info/index.php/AJMS

Key words: Lipid profile, Thyroid hormones, Subclinical hypothyroidism

\section{INTRODUCTION}

Iodine deficiency, thyroid dysfunction, along with prevalence of goiter, is a major public health problem in Nepal. ${ }^{1,3}$ Nepal lies in an area of endemic iodine deficiency, with about $30 \%$ prevalence of thyroid dysfunction from previous studies. ${ }^{4-6}$ Hypothyroidism is defined as a deficiency of thyroid activity. It results from reduced secretion of both thyroxine $\left(\mathrm{T}_{4}\right)$ and tri-iodothyronine $\left(\mathrm{T}_{3}\right)$. Biochemically decrease in $\mathrm{T}_{4}$ and $\mathrm{T}_{3}$ concentrations leads to increased secretion of thyroid stimulating hormone (TSH) from the pituitary gland and an amplified increase in serum TSH. ${ }^{7}$ Hypothyroidism results from inadequate production of thyroid hormones, and is classified as overt or subclinical depending on the degree of clinical severity and the extent of abnormalities in thyroid hormone levels. ${ }^{8}$ Subclinical hypothyroidism $(\mathrm{SH})$ is a hypothyroid condition usually asymptomatic, in which free $\mathrm{T}_{3}$ and $\mathrm{T}_{4}$ levels are within reference range and TSH level is above the reference range, or if a thyrotropin releasing hormone (TRH) test is conducted, there's a greater than normal elevation in TSH response. ${ }^{9}$ Thyroid hormones play important role in regulation of energy homeostasis, glucose and lipid metabolism and regulate some key enzymes of lipoprotein transport. ${ }^{10-12}$ Lipid abnormalities are reported to be more common in patients with overt hypothyroidism and are 
thought to contribute to the disproportionate increase in cardiovascular risk in those persons. $\mathrm{SH}$ is found to be associated with lipid disorders, characterized by normal or slightly elevated total cholesterol, increased LDL and lower HDL. SH is also associated with endothelium dysfunction, aortic atherosclerosis and myocardial infarction. ${ }^{13-15}$ Prevalence of SH in eastern region of Nepal, was 20.42\% and increased Total Cholesterol was associated with increasing age in hypothyroid and sub-clinical hypothyroid subjects in our previous study. ${ }^{16,17}$ The present study was conducted aiming to investigate lipid profile in patients with subclinical hypothyroidism as compared to age and sex matched controls.

\section{MATERIALS AND METHODS}

The present study was conducted in Immunoassay Laboratory, Department of Biochemistry, B.P. Koirala Institute of Health Sciences (BPKIHS), Dharan, Nepal. The study population comprised of, total 40 cases having sub-clinical hypothyroidism and 40 age and sex matched healthy (euthyroid) controls.

\section{Inclusion criteria}

For Cases: All newly diagnosed cases of subclinical hypothyroid patients $(\mathrm{n}=40)$ visiting Immunoassay Laboratory, B.P. Koirala Institute of Health Sciences within the study period were included in this study. Patients with normal $\mathrm{fT}_{3}(2.2-6.5 \mathrm{pmol} / \mathrm{L}), \mathrm{fT}_{4}(10.4-28.4 \mathrm{pmol} / \mathrm{L})$ and TSH level above $6.2 \mathrm{mIU} / \mathrm{L}(0.3-6.2 \mathrm{mIU} / \mathrm{L})$ were considered having subclinical hypothyroidism.

For Controls: Age and sex matched normal euthyroid subjects $(\mathrm{N}=40)$ were included.

\section{Exclusion criteria}

The patients who were diagnosed as hyperthyroid and hypothyroid were not included in this study. Patients on any kinds of medications, hormonal preparations and oral contraceptives/lipid lowering agents were excluded, as well as patients with diabetes mellitus, renal failure, hypertension, any other chronic illness were also excluded.

\section{Thyroid hormones and Lipid Profile Assay}

After 12-14 hours fasting three milliliter blood sample was collected by venipuncture in all subjects in a plain vial. On the same day of collection, serum was separated by centrifugation (REMI Research Centrifuge Model R-23, India) at $2500 \mathrm{rpm}$ for 15 minutes at room temperature and stored at $-20^{\circ} \mathrm{C}$ until analysis. Serum $\mathrm{fT}_{3}$ and $\mathrm{fT}_{4}$ were estimated by competitive Enzyme Linked Immunosorbent Assay (ELISA) and TSH was estimated by sandwich ELISA (Human Diagnostic, Germany). All the parameters of lipid profile, total cholesterol, ${ }^{18}$ triglycerides $(\mathrm{TG}),{ }^{19}$ high density lipoprotein (HDL $)^{20}$ were assayed using enzymatic methods (Human Diagnostic, Germany). Very low density lipoprotein (VLDL) and low density lipoprotein (LDL) cholesterol were calculated using Friedewald's formula. ${ }^{21}$ Reference ranges for lipid parameters were: Total cholesterol $(<5.2 \mathrm{mmol} / \mathrm{L})$, Triglycerides: $(0.7-1.9 \mathrm{mmol} / \mathrm{L}), \mathrm{LDL}$ cholesterol $(<3.4$ $\mathrm{mmol} / \mathrm{L})$, HDL cholesterol $(>1.1 \mathrm{mmol} / \mathrm{L})$, VLDL cholesterol (0.1-0.9 mmol/L), Total cholesterol/HDL $(<5)$. Ethical clearance was approved as per the guidelines of Institutional Ethical Review Board (IERB), B .P. Koirala Institute of Health Sciences, Dharan, Nepal.

\section{Statistical analysis}

Data were entered into Microsoft Excel 2007, and statistical analysis was performed using the statistical package for social sciences (SPSS) version 20 (SPSS Inc. Chicago, USA). Normality of the data was tested using Shapiro-Wilk test. Data were presented as Mean \pm SD. Student ' $t$ ' test was used to compare the mean values between cases and controls. Pearson's correlation test was applied to compare correlation between TSH \& lipid parameters. P value of less than 0.05 was considered as statistically significant at $95 \%$ confidence intervals.

\section{RESULTS}

The mean age of patients (37.42 \pm 13.9$)$ was comparable to that of control's age $(35.10 \pm 10.10)$ years $(\mathrm{P}=0.3)$. There were $35(44 \%)$ female \& $5(6 \%)$ male in cases group and $36(45 \%)$ female \& $4(5 \%)$ male in control group. Significant differences were observed between lipid parameters in case Vs controls: total cholesterol $(4.9 \pm 1.1 \mathrm{Vs} 4.3 \pm 1.0 \mathrm{mmol} / \mathrm{L}$, $\mathrm{P}=0.03)$, triglycerides $(1.9 \pm 0.7 \mathrm{Vs} 1.6 \pm 0.6 \mathrm{mmol} / \mathrm{L}, \mathrm{P}=0.02)$ and LDL cholesterol levels $(3.5 \pm 1.1 \mathrm{Vs} 2.9 \pm 0.9 \mathrm{mmol} / \mathrm{L}$, $\mathrm{P}=0.02)$. In case $\mathrm{Vs}$ controls no significant differences were observed between HDL Cholesterol $(1.1 \pm 0.2 \mathrm{Vs}$ $1.1 \pm 0.7 \mathrm{mmol} / \mathrm{L}, \mathrm{P}=0.07)$, VLDL $(0.9 \pm 0.4$ Vs $0.8 \pm 0.3$ $\mathrm{mmol} / \mathrm{L}, \mathrm{P}=0.1)$ and Cholesterol/HDL ratio $(4.4 \pm 1.4$ Vs $4.06 \pm 0.8, \mathrm{P}=0.1)$. Elevated TSH level was found in cases Vs controls (12.4 \pm 7.0 Vs $2.6 \pm 0.2 \mathrm{mIU} / \mathrm{L}, \mathrm{P}=0.01)$ which was statistically significant. The subjects on control group were euthyroid, however increased $\mathrm{fT}_{3}(3.9 \pm 0.8$ Vs $4.6 \pm 0.8 \mathrm{pmol} / \mathrm{L}, \mathrm{P}=<0.01)$ and $\mathrm{fT}_{4}(17.1 \pm 3.9 \mathrm{Vs}$ 21.2 $\pm .3 .7 \mathrm{pmol} / \mathrm{L}, \mathrm{P}=<0.01)$ were observed in controls than cases, which was statistically significant (Table 1). Total cholesterol, triglycerides and VLDL levels were positively correlated with serum TSH but it was not statistically significant $(r=0.09, P=0.4),(r=0.1, P=0.2),(r=0.04, P=0.6)$ respectively. LDL cholesterol showed highly significant positive correlation $(r=0.2, \mathrm{P}=0.04)$ with serum TSH level. Whereas, HDL cholesterol showed significant negative correlation $(\mathrm{r}=-0.2, \mathrm{P}=0.02)$ with TSH (Table 2$)$. 
Table 1: Biochemical parameters in cases and controls

\begin{tabular}{|c|c|c|c|c|c|c|c|c|c|}
\hline \multirow[t]{2}{*}{ Parameters } & \multicolumn{4}{|c|}{ Cases } & \multicolumn{4}{|c|}{ Controls } & \multirow{2}{*}{$\begin{array}{l}P \text { value } \\
\text { (total) }\end{array}$} \\
\hline & Male & Female & $P$ value & Total $(N=40)$ & Male & Female & $P$ value & Total $(N=40)$ & \\
\hline Total Chlolesterol (mmol/L) & $3.4 \pm 0.5$ & $4.9 \pm 1.0$ & 0.04 & $4.9 \pm 1.1$ & $4.2 \pm 1.1$ & $4.4 \pm 0.9$ & 0.6 & $4.3 \pm 1.0$ & 0.03 \\
\hline Triglycerides (mmol/L) & $1.4 \pm 0.4$ & $1.9 \pm 0.7$ & 0.1 & $1.9 \pm 0.7$ & $1.5 \pm 0.4$ & $1.7 \pm 0.6$ & 0.3 & $1.6 \pm 0.6$ & 0.04 \\
\hline LDL Cholesterol (mmol/L) & $2.2 \pm 0.6$ & $3.6 \pm 0.9$ & 0.008 & $3.5 \pm 1.1$ & $2.8 \pm 1.1$ & $2.9 \pm 0.9$ & 0.7 & $2.9 \pm 0.9$ & 0.03 \\
\hline HDL Cholesterol (mmol/L) & $0.9 \pm 0.1$ & $1.1 \pm 0.2$ & 0.2 & $1.1 \pm 0.2$ & $1.1 \pm 0.1$ & $1.1 \pm 0.1$ & 0.8 & $1.1 \pm 0.7$ & 0.07 \\
\hline VLDL (mmol/L) & $0.7 \pm 0.2$ & $0.9 \pm 0.4$ & 0.3 & $0.9 \pm 0.4$ & $0.7 \pm 0.2$ & $0.8 \pm 0.3$ & 0.3 & $0.8 \pm 0.3$ & 0.1 \\
\hline Cholesterol/HDL & $3.3 \pm 0.8$ & $4.7 \pm 1.5$ & 0.06 & $4.5 \pm 1.5$ & $4.3 \pm 1.1$ & $4.1 \pm 0.9$ & 0.5 & $4.1 \pm 0.9$ & 0.1 \\
\hline $\mathrm{TSH}(\mathrm{mlU} / \mathrm{L})$ & $12.4 \pm 7.9$ & $12.4 \pm 7.1$ & 0.9 & $12.5 \pm 7.1$ & $1.7 \pm 0.9$ & $2.9 \pm 1.4$ & 0.04 & $2.7 \pm 1.3$ & $<0.001$ \\
\hline $\mathrm{fT}_{3}(\mathrm{pmol} / \mathrm{L})$ & $3.6 \pm 0.8$ & $3.9 \pm 0.9$ & 0.4 & $3.9 \pm 0.8$ & $4.7 \pm 0.9$ & $4.6 \pm 0.8$ & 0.8 & $4.6 \pm 0.8$ & $<0.001$ \\
\hline $\mathrm{fT}_{4}^{3}(\mathrm{pmol} / \mathrm{L})$ & $18.5 \pm 4.1$ & $16.9 \pm 3.9$ & 0.4 & $17.1 \pm 3.9$ & $18.8 \pm 3.8$ & $21.6 \pm 3.6$ & 0.1 & $21.2 \pm 3.7$ & $<0.001$ \\
\hline
\end{tabular}

Student ' $t$ ' test was applied for male/female, cases/controls and total at $95 \%$ confidence Intervals

\begin{tabular}{|c|c|c|c|c|c|c|}
\hline \multirow[t]{2}{*}{ Parameters } & \multicolumn{2}{|c|}{ Case } & \multicolumn{2}{|c|}{ Control } & \multicolumn{2}{|c|}{ Total } \\
\hline & $r$ value & $P$ value & $r$ value & $P$ value & $r$ value & $P$ value \\
\hline $\begin{array}{l}\text { Total } \\
\text { cholesterol }\end{array}$ & -0.2 & 0.2 & 0.2 & 0.2 & 0.09 & 0.4 \\
\hline Triglycerides & -0.08 & 0.7 & 0.24 & 0.1 & 0.1 & 0.2 \\
\hline $\begin{array}{l}\text { LDL } \\
\text { cholesterol }\end{array}$ & -0.17 & 0.3 & 0.2 & 0.2 & $0.2^{*}$ & 0.04 \\
\hline $\begin{array}{l}\text { HDL } \\
\text { cholesterol }\end{array}$ & -0.2 & 0.2 & 0.06 & 0.7 & $0.2^{*}$ & 0.02 \\
\hline VLDL & 0.14 & 0.4 & 0.2 & 0.1 & 0.04 & 0.6 \\
\hline
\end{tabular}

\section{DISCUSSION}

The Wickham Survey ${ }^{8}$ and the Colorado study ${ }^{11}$ have shown prevalence of $\mathrm{SH}$ in $7.5 \%$ males and $3.1 \%$ females in general population. In these surveys, the mean total cholesterol and LDL cholesterol progressively increased with increasing levels of serum TSH and hypercholesterolemia was associated with mild elevations of TSH levels. In some studies from India: i) Singh K et al, 2011 showed significant increase in triglycerides and VLDL cholesterol and nominal increases in serum cholesterol, LDL and HDL levels in SH patients as compared to controls, ${ }^{22}$ ii) Bandyopadhyay et al, 2006 reported significant elevations in $\mathrm{SH}$ patients as compared to controls, and increased levels of serum lipoprotein (a) in age above 20 years and total cholesterol, triglyceride and LDL in age groups of 40-50 years, ${ }^{23}$ iii) Asranna A et al, 2012 showed increased level of total cholesterol and LDL levels and no significant elevations in VLDL and triglyceride levels and HDL cholesterol was lower in SH patients than controls but not statistically significant. ${ }^{24}$ In few other studies, total cholesterol and LDL Cholesterol were found to be elevated in cases as compared with controls. ${ }^{25-27}$ Our findings are in agreement with these studies, showing that dyslipidemia is significantly associated with subclinical hypothyroidism. In the present study, total cholesterol level was found to be significantly higher in cases than controls. It was observed that TG and LDL cholesterol are significantly increased in cases and a highly significant positive correlation was also observed between LDL cholesterol and TSH levels. Which is in concordance with previous studies, due to the fact that, serum cholesterol levels are increased in hypothyroidism, due to effects of thyroid hormones in LDL synthesis and degradation. ${ }^{28}$ HDL cholesterol and VLDL did not differ significantly as compared to controls. No significant relationship was found between cholesterol, HDL, or LDL levels and SH. Some studies have shown an increase in HDL cholesterol levels in $\mathrm{SH}$ whereas others show either no change or decrease. ${ }^{22-24}$ Plasma HDL concentration is reported normal or elevated in severe hypothyroidism, because thyroid hormones participate in regulation of Cholesterol Ester Transfer Protein (CETP) and Hepatic Lipase (HL). It has also been shown in some studies that correction of hypothyroidism with the thyroid hormone levothyroxine reverses the lipid abnormalities. ${ }^{92}$ On the basis of outcome of the present study, it is proposed that the measurement of serum TSH be included in the screening of patients with dyslipidemia. Patients diagnosed with SH may be followed up to see whether the patient gets converted to overt disease state. The effect of treatment of thyroid disorders on the restoration of lipid metabolism has immense potential clinical implication in developing therapeutic guidelines and needing further elaborative studies. The alterations of lipids parameters can lead to development of atherosclerosis, which has serious consequences like development of coronary artery disease, stroke, etc. ${ }^{29,30}$ In the present study, total cholesterol, triglycerides and LDL cholesterol levels were significantly higher in cases as compared to controls though the HDL and VLDL levels did not differ significantly. The results of the present study suggest that cases of SH are at risk of dyslipidemia as compared to controls. Large population based studies are needed to generalize these findings and establish the therapeutic guidelines for implementing lipid lowering agents in subclinical hypothyroidism, also it is essential to consider the associated genetic factors related to $\mathrm{SH}$ and dyslipidemia in further studies. 


\section{ACKNOWLEDGEMENT}

We would like to cordially thank Department of Biochemistry, B.P. Koirala Institute of Health Sciences for supporting this study.

\section{REFERENCES}

1. Baral N, Lamsal M, Koner BC and Koirala S. Thyroid dysfunction in eastern Nepal. Southeast Asian J Trop Med Public Health 2002;33(3):638-641.

2. Nepal AK, Shakya PR, Gelal B, Lamsal M, Brodie DA and Baral N. Household Salt lodine Content Estimation with the Use of Rapid Test Kits and lodometric Titration Methods. J Clin Diagn Res 2013;7(5):892-895.

3. Gelal B, Chaudhari RK, Nepal AK, Sah GS, Lamsal M, Brodie DA, et al. lodine deficiency disorders among primary school children in eastern Nepal. Indian J Pediatr 2011;78(1):45-48.

4. Nepal AK, Khatiwada S, Shakya PR, Gelal B, Lamsal M, Brodie DA, et al. lodine status after iodized salt supplementation in school children of eastern Nepal. Southeast Asian J Trop Med Public Health 2013;44(6):1072-1078.

5. Gelal B, Aryal M, Das BK, Bhatta B, Lamsal M and Baral N. Assessment of iodine nutrition status among school age children of Nepal by urinary iodine assay. Southeast Asian J Trop med Public Health 2009;40(3):538-543.

6. Mahato RV, Nepal AK, Gelal B, Poudel B, Yadav BK and Lamsal M. Spectrum of thyroid dysfunction in patients visiting kantipur hospital, kathmandu, Nepal. Mymensingh Med J 2013;22(1):164-169.

7. Seely EW and William GH. The Heart in Endocrine Disorder. 6th ed. Eugene Braunward DP, Zipes, editor. Phildelphia:W. Saunders accompany;2001.

8. Tunbridge WM, Evered DC, Hall R, Appleton D, Brewis M, Clark F, et al. The spectrum of thyroid disease in a community:the Whickham survey. Clin Endocrinol 1977;7(6):481-493.

9. Surks MI, Ortiz E, Daniels GH, Sawin CT, Col NF, Cobin RH, et al. Subclinical thyroid disease:scientific review and guidelines for diagnosis and management. JAMA 2004;291(2):228-238.

10. Duntas LH. Thyroid disease and lipids. Thyroid 2002;12(4):287293.

11. Canaris GJ, Manowitz NR, Mayor G and Ridgway EC. The Colorado thyroid disease prevalence study. Arch Intern Med 2000;160(4):526-534.

12. Friis $T$ and Pedersen LR. Serum lipids in hyper- and hypothyroidism before and after treatment. Clin Chim Acta 1987;162(2):155-163.

13. Morris MS, Bostom AG, Jacques PF, Selhub J and Rosenberg IH. Hyperhomocysteinemia and hypercholesterolemia associated with hypothyroidism in the third US National Health and Nutrition Examination Survey. Atherosclerosis 2001;155(1):195-200.

14. Vierhapper H, Nardi A, Grosser P, Raber W and Gessl A. Lowdensity lipoprotein cholesterol in subclinical hypothyroidism. Thyroid 2000;10(11):981-984.
15. Pirich $\mathrm{C}$, Mullner $\mathrm{M}$ and Sinzinger $\mathrm{H}$. Prevalence and relevance of thyroid dysfunction in 1922 cholesterol screening participants. J Clin Epidemiol 2000;53(6):623-629.

16. Rohil V, Mishra AK, Shrewastava MK, Mehta KD, Lamsal M, Majhi S, et al. Subclinical hypothyroidism in eastern Nepal: A hospital based study. Kathmandu University Medical Journal 2010;8(10):231-237.

17. Pokharel S, Baral N, Sridhar MG and Lamsal M. Age related changes in cholesterol level among the patients with subclinical hypothyroidism in Eastern Nepal. Nepal Med Coll J 2006;8(3):185-189.

18. Homolka J. Enzymatic estimation of cholesterol. Cas Lek Cesk 1977;116(45):1387-1389.

19. Baca $A M$ and Warnick GR. Estimation of LDL-associated apolipoprotein $\mathrm{B}$ from measurements of triglycerides and total apolipoprotein B. Clinical chemistry 2008;54(5):907-910.

20. Izzo C, Grillo F and Murador E. Improved method for determination of high-density-lipoprotein cholesterol I. Isolation of high-density lipoproteins by use of polyethylene glycol 6000 . Clin Chem 1981;27(3):371-374.

21. Friedewald WT, Levy RI and Fredrickson DS. Estimation of the concentration of low-density lipoprotein cholesterol in plasma, without use of the preparative ultracentrifuge. Clin Chem 1972;18(6):499-502.

22. Singh $\mathrm{KL}$ and Singh S. Alterations in lipid fractions in subclinical Hypothyroidism in North Indian population. Indian J Fundam Life Sci 2011;1:127-132.

23. Bandyopadhyay SK, Basu AK, Pal SK, Roy P, Chakrabarti $\mathrm{S}$, Pathak HS, et al. A study on dyslipidaemia in subclinical hypothyroidism. J Indian Med Assoc 2006;104(11):622-624.

24. Asranna A, Taneja RS and Kulshreshta B. Dyslipidemia in subclinical hypothyroidism and the effect of thyroxine on lipid profile. Indian J Endocrinol Metab 2012;16(Suppl 2):S347-S349.

25. Miura S, litaka M, Yoshimura H, Kitahama S, Fukasawa N, Kawakami $Y$, et al. Disturbed lipid metabolism in patients with subclinical hypothyroidism: effect of L-thyroxine therapy. Intern Med 1994;33(7):413-417.

26. Kung AW, Pang RW and Janus ED. Elevated serum lipoprotein(a) in subclinical hypothyroidism. Clin Endocrinol 1995;43(4):445-449.

27. Yildirimkaya M, Ozata M, Yilmaz K, Kilinc C, Gundogan MA and Kutluay T. Lipoprotein(a) concentration in subclinical hypothyroidism before and after levo-thyroxine therapy. Endocr J 1996;43(6):731-736.

28. Hueston WJ and Pearson WS. Subclinical hypothyroidism and the risk of hypercholesterolemia. Ann Fam Med 2004;2(4):351355.

29. Genest J, McPherson R, Frohlich J, Anderson T, Campbell N, Carpentier A, et al. Canadian Cardiovascular Society/Canadian guidelines for the diagnosis and treatment of dyslipidemia and prevention of cardiovascular disease in the adult - 2009 recommendations. Can J Cardiol 2009;25(10):567-579.

30. Third Report of the National Cholesterol Education Program (NCEP) Expert Panel on Detection, Evaluation, and Treatment of High Blood Cholesterol in Adults (Adult Treatment Panel III) final report. Circulation 2002;106(25):3143-3421.

\section{Authors Contribution:}

RY - designed the study, performed the laboratory tests and drafted the manuscript; AKN - analysed the data and drafted the manuscript; VR - designed the experiments and reviewed the manuscript; BG - contributed to the study design; RKC - contributed to the study design; PJ - contributed to the study design; SS - contributed to the study design; ML - designed the experiments and reviewed the manuscript; NB - designed the experiments and reviewed the manuscript.

Source of Support: Department of Biochemistry, B.P. Koirala Institute of Health Sciences, Dharan, Nepal, Conflict of Interest: None declared. 